\title{
Prevalence of working smoke alarms in local authority inner city housing: randomised controlled trial
}

\author{
Diane Rowland, Carolyn DiGuiseppi, Ian Roberts, Katherine Curtis, Helen Roberts, Laura Ginnelly, \\ Mark Sculpher, Angela Wade
}

\begin{tabular}{l}
\hline Editorial by Pless \\
\hline \\
Public Health \\
Intervention \\
Research Unit, \\
London School of \\
Hygiene and \\
Tropical Medicine, \\
London \\
WC1B 3DP \\
Diane Rowland \\
research fellow \\
Ian Roberts \\
professor of \\
epidemiology and \\
public health \\
Department of \\
Preventive Medicine \\
and Biometrics, \\
University of \\
Colorado Health \\
Sciences Center, \\
Denver, CO 80262, \\
USA \\
Carolyn DiGuiseppi \\
associate professor
\end{tabular}

Institute of Health Sciences, City University, London EC1A 7QN

Katherine Curtis research officer

Helen Roberts professor of child health

Centre for Health Economics, University of York, York YO10 5DD

Laura Ginnelly research fellow Mark Sculpher professor of health economics

Centre for Paediatric Epidemiology and Biostatistics, Institute of Child Health, London WC1N 3JH Angela Wade senior lecturer in medical statistics

Correspondence to: I Roberts

Ian.Roberts@

LSHTM.ac.uk

BMJ 2002;325:998-1001

\begin{abstract}
Objectives To identify which type of smoke alarm is most likely to remain working in local authority inner city housing, and to identify an alarm tolerated in households with smokers.

Design Randomised controlled trial. Setting Two local authority housing estates in inner London.

Participants 2145 households.

Intervention Installation of one of five types of smoke alarm (ionisation sensor with a zinc battery; ionisation sensor with a zinc battery and pause button; ionisation sensor with a lithium battery and pause button;

optical sensor with a lithium battery; or optical sensor with a zinc battery).

Main outcome measure Percentage of homes with any working alarm and percentage in which the alarm installed for this study was working after 15 months. Results 54.4\% (1166/2145) of all households and $45.9 \%$ (465/1012) of households occupied by smokers had a working smoke alarm. Ionisation sensor, lithium battery, and there being a smoker in the household were independently associated with whether an alarm was working (adjusted odds ratios 2.24 (95\% confidence interval 1.75 to 2.87$), 2.20$ (1.77 to 2.75 ), and 0.62 (0.52 to 0.74$)$ ). The most common reasons for non-function were missing battery (19\%), missing alarm (17\%), and battery disconnected (4\%). Conclusions Nearly half of the alarms installed were not working when tested 15 months later. Type of alarm and power source are important determinants of whether a household had a working alarm.
\end{abstract}

\section{Introduction}

Every year about 500 people die and 15000 people are injured in house fires in England and Wales. ${ }^{1}$ Children and elderly people are at greatest risk, and risk is strongly associated with socioeconomic group. ${ }^{2}$ Smoke alarms can reduce the risk of death in a fire. ${ }^{3}$ In 1999 , $81 \%$ of British households reported having an alarm ${ }^{4}$; in two deprived inner London boroughs, however, only $16 \%$ of local authority homes had working smoke alarms. ${ }^{5}$ Householders may remove or disconnect batteries because of warnings that batteries are low or to avoid false alarms from cooking or tobacco smoke. ${ }^{6}$ Because smoking is a strong risk factor for death from fire, increasing the prevalence of working alarms in households with smokers is particularly important. ${ }^{7}$

Smoke alarms differ by sensor type (ionisation or optical) and power source (mains or battery operated). Because ionisation sensors are sensitive to small smoke particles-for example, from cigarettes or cookingfalse alarms are common; some ionisation alarms have a pause button which enables the alarm to be temporarily silenced. ${ }^{8}$ Alarms using optical sensors, which are more expensive, are less sensitive to small smoke particles and may cause fewer nuisance alarms.

Most battery operated alarms use zinc or alkaline batteries costing about $£ 2(\$ 3 ; € 3)$ and lasting about a year. Lithium batteries, lasting up to 10 years and costing $£ 7$, are available.

No studies have identified which type of alarm is most likely to remain working the longest in local authority households. To measure how the different types of alarms and power sources affect the prevalence of working alarms we carried out a randomised controlled trial. Qualitative work explored the perspectives of users and process issues.

\section{Methods}

We recruited participants from a local authority housing estate in the London Borough of Camden between November 1999 and August 2000. We sent an introductory letter inviting households to participate which we followed up with a visit. We asked residents fluent in relevant languages to encourage the substantial $(23 \%)$ non-English speaking population to participate. Participants gave written consent to be randomly allocated one of five types of smoke alarm, to have the alarm installed, and to have an interview and inspection 15 months later.

We collected information about tenure, the number of adult occupiers, the number of smokers, whether a working alarm was already present, and whether the kitchen was open plan for each property. Office staff entered participants' data into the MINIM programme, which randomly allocated alarm types using minimisation to achieve a balance regarding these five factors. ${ }^{9}$

\section{Intervention}

The MINIM programme randomised participants to alarms containing $(a)$ an ionisation sensor and a zinc battery; (b) an ionisation sensor, a zinc battery, and a pause button; $(c)$ an ionisation sensor, a lithium battery, and a pause button; $(d)$ an optical sensor and a lithium battery; (e) an optical sensor and a zinc battery. We allocated alarms in the ratio 7:7:3:3:4 for these categories (figure). Alarms were installed following manufacturer's guidelines.

We gave participants written and verbal instructions on maintenance including monthly testing, annual vacuuming, and, as appropriate, use of the pause button and annual battery replacement. Reminders to change the battery were sent to participants with alarms powered by zinc batteries one year after installation.

\section{Assessment and analysis of outcome}

At follow up, 15 months after installation, we visited each household unannounced and sought permission to inspect and test the alarm using a standardised 


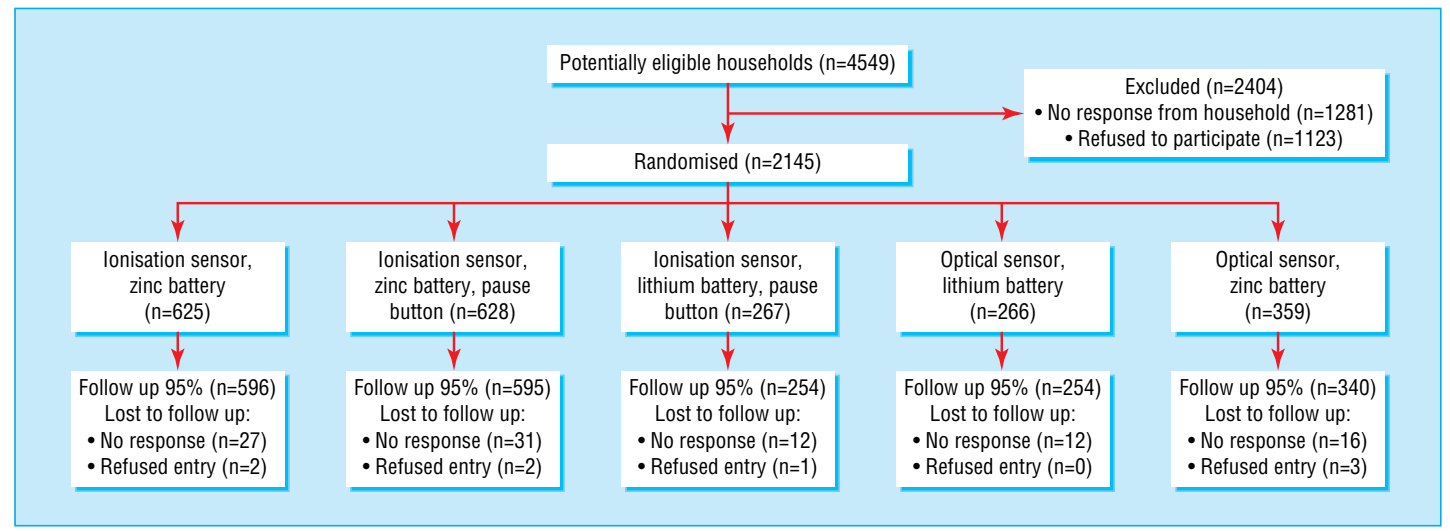

Flow of households through the trial

smoke test. ${ }^{10}$ If the alarm failed we checked if the battery was present, connected, and working. Replacement batteries were offered to all recipients of alarms powered by zinc batteries. Because batteries, sensors, and casings were not identical, the trained project officers were not blinded. If access to the property was not gained, we assumed alarms were not working.

The sample size and allocation ratio that we chose gave at least an $80 \%$ chance of showing a $10 \%$ difference in the prevalence of working alarms at the $5 \%$ significance level. We used logistic regression to calculate the effects on the probability that the allocated alarm was working. We also investigated whether the prevalence of working alarms after 15 months was related to whether the occupiers were smokers or had open plan kitchens. Analyses were based on original alarm allocation. The Institute of Child Health Research Ethics Committee approved the design of the study.

\section{Results}

Of 4549 potentially eligible households, 3268 (71.8\%) were contacted, of which $2145(65.6 \%)$ agreed to participate. The figure shows the flow of participants through the trial. Table 1 gives baseline characteristics.

Of the 2145 randomised households, 2039 (95.1) were assessed, and 2004 (93.4) had a smoke alarms installed. A total of 1166 (54.4\%) had a working alarm. The alarm fitted for this study was working in 1097 (51.1\%) households. Of 1012 households with at least one smoker, 465 (45.9\%) had working alarms; of 506 households with open plan kitchens, 253 (50.0\%) had working alarms.

The households given alarms with an ionisation sensor, lithium batteries, and a pause button were the most likely to have a working alarm $(184 / 267 ; 69 \%)$ and to have a working study alarm $(175 ; 66 \%)$ (table 2$)$. The households given optical alarms with a zinc battery were least likely to have any working alarm $(148 / 359 ; 41 \%)$ or a working study alarm (131/359; $36 \%)$.

Smoke alarms were less likely to be working in households with at least one smoker, irrespective of the type of alarm. The percentage of households with at least one smoker with any working alarm was greatest for alarms with ionisation sensors, lithium batteries, and pause buttons $(127 ; 59 \%)$ and lowest for alarms with optical sensors and zinc batteries (53; 31\%). In households with at least one smoker, the proportion of alarms working was lower for optical alarms (38\%) than for ionising alarms (48\%). The proportion of households with a working alarm was lower in properties with open plan kitchens $(253 / 506 ; 50.0 \%)$ compared with households with enclosed kitchens (913/1639; 55.7\%).

Alarms with an ionisation sensor (odds ratios 1.45; $95 \%$ confidence interval 1.20 to 1.74 ) or a lithium battery $(1.67 ; 1.36$ to 2.03$)$ were more likely than not to be working.

Having a pause button was not related to the chance of an alarm working (1.08; 0.91 to 1.29$)$. The alarm was significantly less likely to be working in households with at least one smoker $(0.63 ; 0.53$ to

Table 1 Characteristics of households on local authority estates in London at baseline. Values are numbers (percentages)

\begin{tabular}{|c|c|c|c|c|c|}
\hline \multirow[b]{3}{*}{ Characteristic } & \multicolumn{3}{|c|}{ Ionisation sensor } & \multicolumn{2}{|c|}{ Optical sensor } \\
\hline & \multicolumn{2}{|c|}{ Zinc battery } & \multirow{2}{*}{$\begin{array}{l}\text { Lithium battery, pause button } \\
\text { ( } \mathrm{n}=267)\end{array}$} & \multirow[b]{2}{*}{ Lithium battery $(n=266)$} & \multirow[b]{2}{*}{ Zinc battery $(\mathrm{n}=359)$} \\
\hline & No pause button ( $n=625)$ & Pause button $(n=628)$ & & & \\
\hline Working alarm & $74(12)$ & $73(12)$ & $31(12)$ & $31(12)$ & $41(11)$ \\
\hline Open plan kitchen & $148(24)$ & $149(24)$ & $62(23)$ & $60(23)$ & $87(24)$ \\
\hline$\geqslant 1$ smoker & $295(47)$ & $295(47)$ & $127(48)$ & $125(47)$ & $170(47)$ \\
\hline Two adults only & $296(47)$ & $299(47)$ & $127(48)$ & $126(47)$ & $170(47)$ \\
\hline Leaseholder & $84(13)$ & $83(13)$ & $35(13)$ & $34(13)$ & $48(13)$ \\
\hline Aged $\geqslant 65$ years & $162(26)$ & $157(25)$ & $69(26)$ & $72(27)$ & $92(26)$ \\
\hline Aged $\leqslant 5$ years & $144(23)$ & $124(20)$ & $63(24)$ & $57(21)$ & $82(23)$ \\
\hline \multicolumn{6}{|l|}{ Ethnic group: } \\
\hline White & $388(61)$ & $404(64)$ & $159(60)$ & $153(58)$ & $231(64)$ \\
\hline Bangladeshi & $92(15)$ & $83(13)$ & $37(14)$ & $43(16)$ & $38(11)$ \\
\hline Black African & $48(8)$ & $61(10)$ & $30(11)$ & $17(6)$ & $39(11)$ \\
\hline
\end{tabular}


Table 2 Results of alarm function 15 months post-installation

\begin{tabular}{|c|c|c|c|c|c|c|c|c|c|c|c|c|c|c|c|}
\hline & \multicolumn{3}{|c|}{ Ionisation, zinc battery } & \multicolumn{3}{|c|}{$\begin{array}{c}\text { Ionisation, zinc battery, pause } \\
\text { button }\end{array}$} & \multicolumn{3}{|c|}{$\begin{array}{c}\text { Ionisation, lithium battery, } \\
\text { pause button }\end{array}$} & \multicolumn{3}{|c|}{ Optical, lithium battery } & \multicolumn{3}{|c|}{ Optical, zinc battery } \\
\hline & $\begin{array}{c}\text { All } \\
\text { homes } \\
(\mathrm{n}=625)\end{array}$ & $\begin{array}{c}\text { Smoker } \\
\text { occupier } \\
(\mathrm{n}=295)\end{array}$ & $\begin{array}{c}\text { Open } \\
\text { plan } \\
\text { kitchen } \\
(\mathrm{n}=148)\end{array}$ & $\begin{array}{c}\text { All } \\
\text { homes } \\
(\mathrm{n}=628)\end{array}$ & $\begin{array}{l}\text { Smoker } \\
\text { occupier } \\
(\mathrm{n}=295)\end{array}$ & $\begin{array}{c}\text { Open } \\
\text { plan } \\
\text { kitchen } \\
(\mathrm{n}=149)\end{array}$ & $\begin{array}{c}\text { All } \\
\text { homes } \\
(\mathrm{n}=267)\end{array}$ & $\begin{array}{c}\text { Smoker } \\
\text { occupier } \\
(\mathrm{n}=127)\end{array}$ & $\begin{array}{c}\text { Open } \\
\text { plan } \\
\text { kitchen } \\
(\mathrm{n}=62)\end{array}$ & $\begin{array}{c}\text { All } \\
\text { homes } \\
(\mathrm{n}=266)\end{array}$ & $\begin{array}{l}\text { Smoking } \\
\text { occupier } \\
(n=125)\end{array}$ & $\begin{array}{c}\text { Open } \\
\text { plan } \\
\text { kitchen } \\
(n=60)\end{array}$ & $\begin{array}{c}\text { All } \\
\text { homes } \\
(\mathrm{n}=359)\end{array}$ & $\begin{array}{c}\text { Smoker } \\
\text { occupier } \\
(\mathrm{n}=170)\end{array}$ & $\begin{array}{c}\text { Open } \\
\text { plan } \\
\text { kitchen } \\
(\mathrm{n}=87)\end{array}$ \\
\hline Any alarm working & $363(58)$ & $148(50)$ & $78(53)$ & $311(50)$ & $128(43)$ & $71(48)$ & $184(69)$ & 75 (59) & $40(65)$ & $160(60)$ & $61(49)$ & $29(48)$ & $148(41)$ & $53(31)$ & $35(40)$ \\
\hline Study alarm working & $350(56)$ & $147(50)$ & 77 (52) & $293(47)$ & $124(42)$ & $68(46)$ & $175(66)$ & $73(57)$ & $39(63)$ & $148(56)$ & $61(49)$ & $29(48)$ & $131(36)$ & $51(30)$ & $35(40)$ \\
\hline Study alarm absent & $113(18)$ & $58(20)$ & $29(20)$ & $80(13)$ & $38(13)$ & $18(12)$ & $49(18)$ & $28(22)$ & $9(15)$ & $56(21)$ & $32(26)$ & $18(30)$ & $67(19)$ & $35(21)$ & $16(18)$ \\
\hline Battery missing & $97(16)$ & 57 (19) & $22(15)$ & $180(29)$ & $98(33)$ & $46(31)$ & $4(1)$ & $2(2)$ & $1(2)$ & $33(12)$ & $16(13)$ & $7(12)$ & $103(29)$ & $53(31)$ & $24(28)$ \\
\hline Battery dead $^{*}$ & $4(<1)$ & $2(<1)$ & 0 & $9(1)$ & $4(1)$ & $1(<1)$ & $1(<1)$ & $1(<1)$ & $1(2)$ & $6(2)$ & $4(3)$ & 0 & $21(6)$ & $11(6)$ & $6(7)$ \\
\hline
\end{tabular}

${ }^{*}$ Not mutually exclusive.

0.75). Having an enclosed kitchen was not associated with greater prevalence of working alarms (1.12; 0.92 to 1.37 ).

In a multivariate model, ionisation sensor, lithium battery, and smoking were all independently associated with whether alarms worked (adjusted odds ratios 2.24 (1.75 to 2.87 ), 2.20 (1.77 to 2.75 ), and 0.62 (0.52 to $0.74)$, respectively). Presence of a pause button had a significant negative effect once these factors were taken into account $(0.68 ; 0.55$ to 0.85$)$. There were no significant interactions.

The most common reasons for alarms not working among all 2145 households were missing alarm (365; $17.0 \%)$, missing battery $(417 ; 19.4 \%)$, and disconnected battery $(79 ; 3.7 \%)$. In smoking households the pattern was similar. Among alarms powered by zinc batteries, low battery warning signals and reported changing of the battery were more common when alarms had optical sensors $(67 / 359(19 \%)$ v 93/359 (26\%)) and ionisation sensors and pause buttons (136/628 (21.7) v 156/ $628(24.8 \%))$ than other alarms with ionisation sensors $(50 / 625(8.0 \%)$ v 81/625 (13.0\%)).

\section{Discussion}

Nearly half of the smoke alarms installed in local authority housing were not working 15 months after installation; $40 \%$ were missing or had been disabled by tenants. Some types of alarm were more likely to be working than others; alarms using an ionisation sensor and a 10 year lithium battery were most likely to remain working $(69 \%)$.

\section{Strengths and weaknesses}

Trial allocation was well concealed, potential known confounders were balanced in randomisation, an intention to treat analysis was carried out, and outcome was assessed for $95 \%$ of randomised participants. Outcome assessment could not be blinded to alarm type and we cannot exclude the possibility of assessor bias. ${ }^{11}$ In initial discussions with fire safety policy makers, we were advised that a $10 \%$ increase in the prevalence of working alarms would have important implications: we accounted for this in determining the trial size. Because the number of participants recruited and followed up was greater than anticipated, the trial had the power to detect differences of this magnitude. Conversely, the proportion of potentially eligible households taking part (47\%) was less than expected, and this may impact on the extent to which the results can be generalised. We cannot predict the proportion of alarms working in households that were not contacted, although it is reasonable to predict that a

\section{What is already known on this topic}

Functioning smoke alarms can reduce the risk of death in the event of a house fire

Many local authorities install smoke alarms in their properties

Several different types of smoke alarm are available

\section{What this study adds}

Only half of the smoke alarms installed in local authority housing were still working 15 months later

Ionising smoke alarms with long life lithium batteries were most likely to remain functioning

Installing smoke alarms may not be an effective use of resources

lithium battery smoke alarm would be most effective. We also anticipate that many tenants who refused participation in the trial would also refuse free installation of a smoke alarm if it was offered as part of a community fire prevention programme.

\section{Relation to other studies}

A systematic review of interventions to promote the ownership and working of residential smoke alarms identified 26 completed trials of which 13 were randomised. ${ }^{12}$ None examined the effect of smoke alarm sensor and power source on function. A similar randomised trial of the effect of alarm type on function is currently under way in the United States (in Seattle). This will provide insight into the extent to which the results of our trial can be generalised to other settings.

\section{What the results might mean}

A randomised trial of giving smoke alarms away showed that many tenants failed to install the alarms. ${ }^{13}$ The government currently advises local authorities to install battery powered smoke alarms in their properties. ${ }^{14}$ Our results support using alarms with ionisation sensors powered by lithium batteries. Alarms with optical sensors and pause buttons for reducing nuisance alarm problems are not more effective despite their theoretical advantages (and seem to need extra battery power).

It is a concern that even alarms with ionisation sensors powered by lithium batteries were not working after 15 months in as many as 30\% of households (40\% 
of households occupied by smokers). Installing smoke alarms may not be the best use of the limited resources of local authorities; analyses of the cost effectiveness of such programmes are needed.

Smoke alarms that are less sensitive to cooking and cigarette smoke but still able to give early warning of a house fire merit investigation. Alternatively, sprinkler systems may be a more effective way to reduce the risk of injury due to fire..$^{15}$

We thank the tenants of Camden's Regent's Park Estate and Somers Town Estate. We contacted all participating households to inform them of the trial results. We also thank Camden and Islington Health Authority, particularly Suzanne Slater and Maggie Barker, and Camden Housing Department.

Contributors: All authors participated in study conception and design, revised the manuscript critically for intellectual content, and approved the final version. DR, CD, IR, and AW analysed and interpreted results. DR oversaw programme implementation and data collection, and drafted the manuscript. Charlotte Seirberg revisited households and inspected alarms at follow up. $\mathrm{IR}$ is guarantor.

Funding: Medical Research Council (ISRCTN 47572799). Camden and Islington Health Action Zone, the West Euston Partnership, and the Joan Dawkins Fund paid for the smoke alarms and their installation.

Competing interests: None declared.

1 Watson L, Gamble J. Fire statistics: United Kingdom 1998. London: Government Statistical Service, September 1999. (Home Office Statistical Bulletin Issue 15/99.) www.homeoffice.gov.uk/rds/pdfs/hosb1599.pdf tin Issue $15 / 99$.
(accessed 19 Sep 2002)
2 DiGuiseppi C, Edwards P, Godward C, Roberts I, Wade A. Urban residential fire and flame injuries: a population-based study. Inj Prer 2000;6:250-4.

3 Runvan CW, Bangdiwala SI, Linzer MA, Sacks IJ, Butts J. Risk factors for fatal residential fires. $N$ Engl Med J 1992;327:859-63.

4 National Statistics. Britain Update: November 2000. London: National Statistics, 2000. www.statistics.gov.uk/onlineproducts/britainupdate. asp\#housing (accessed 19 Sep 2002).

5 DiGuiseppi C, Roberts I, Speirs N. Smoke alarm installation and function in inner London council housing. Arch Dis Child 1999;81:400-3.

6 Marriott MD. Reliability and effectiveness of domestic smoke alarms. London: Home Office Fire Research and Development Group, 1994. (Research report No 58.)

7 Budd T, Mayhew P. Fires in the home in 1995: results from the British crime survey. London: Government Statistical Service, 1997.

8 Home Office. Wake up! Get a smoke alarm. London: Stationery Office, 1995

9 Evans S, Day S, Royston P. Minimisation programme for allocating patients to treatments in clinical trials. London: Department of Clinical Epidemiology, The London Hospital Medical College.

10 Bosley K. Assessment of domestic smoke alarm tests. London: Home Office Fire Research and Development Group, 1997. (Research report No 75.) 11 Schulz KF, Chalmers I, Hayes RJ, Altman DG. Dimensions of methodological quality associated with estimates of treatment effects in controlled trials. JAMA 1995;273:408-12.

12 DiGuiseppi C, Higgins JPT. Interventions for promoting smoke alarm ownership and function (Cochrane review). In: The Cochrane Library, Issue 4. Oxford: Update Software, 2001.

13 DiGuiseppi C, Roberts I, Wade A, Sculpher M, Edwards P, Godward C, et al. Incidence of fires and related injuries after giving out free smoke alarms: cluster randomised controlled trial. $B M J$ 2002;325:995-7.

14 Office of the Deputy Prime Minister. Housing and housing policy: smoke alarms in local authority housing. London: ODPM, 2001. www.housing.dtlr.gov.uk/information/fire/index.htm (accessed $19 \mathrm{Sep}$ 2002).

5 Kay RL, Baker SP. Let's emphasize fire sprinklers as an injury prevention technology. Inj Prev 2000;6:72-3.

(Accepted 15 August 2002)

\section{Effect of patients' age on management of acute intracranial haematoma: prospective national study}

Philip T Munro, Rik D Smith, Timothy R J Parke

\begin{abstract}
Objective To determine whether the management of head injuries differs between patients aged $\geqslant 65$ years and those $<65$.

Design Prospective observational national study over four years.

Setting 25 Scottish hospitals that admit trauma patients.

Participants 527 trauma patients with extradural or acute subdural haematomas.

Main outcome measures Time to cranial computed tomography in the first hospital attended, rates of transfer to neurosurgical care, rates of neurosurgical intervention, length of time to operation, and mortality in inpatients in the three months after admission.

Results Patients aged $\geqslant 65$ years had lower survival rates than patients $<65$ years. Rates were $15 / 18$ $(83 \%) v 165 / 167(99 \%)$ for extradural haematoma $(\mathrm{P}=0.007)$ and $61 / 93(66 \%)$ v 229/249 $(92 \%)$ for acute subdural haematoma $(\mathrm{P}<0.001)$. Older patients were less likely to be transferred to specialist neurosurgical care $(10(56 \%) v 142(85 \%)$ for extradural haematoma $(\mathrm{P}=0.005)$ and $56(60 \%) v 192(77 \%)$ for subdural haematoma $(\mathrm{P}=0.004))$. There was no significant
\end{abstract}

difference between age groups in the incidence of neurosurgical interventions in patients who were transferred. Logistic regression analysis showed that age had a significant independent effect on transfer and on survival. Older patients had higher rates of coexisting medical conditions than younger patients, but when severity of injury, initial physiological status at presentation, or previous health were controlled for in a log linear analysis, transfer rates were still lower in older patients than in younger patients $(\mathrm{P}<0.001)$. Conclusions Compared with those aged under 65 years, people aged 65 and over have a worse prognosis after head injury complicated by intracranial haematoma. The decision to transfer such patients to neurosurgical care seems to be biased against older patients.

\section{Introduction}

Major trauma, particularly serious head injury, is associated with high mortality in people over 65 years. ${ }^{1}$ It has been suggested that in older patients with a Glasgow coma score of 8 or less, it is more appropriate to err on the side of inactivity and withhold intensive treatment. ${ }^{12}$ However, up to $60 \%$ of older patients with head injuries can make a full recovery ${ }^{3}$ and take up no 